\title{
Prestige is factored into journal ratings
}

Journal rankings should measure quality, not just quantity, say researchers who are proposing a new way to assess the status of science publications. Whereas the commonly used impact factor simply measures the number of citations per paper, the researchers say their ranking scheme also measures the significance of those citations, giving a truer measure of a journal's standing in the community.

Ranking journals and publications is not just an academic exercise. Such schemes are increasingly used by funding agencies to assess the research of individuals and departments. They also serve as a guide for librarians choosing which journals to subscribe to. All this puts pressure both on researchers to publish in journals with high rankings and on journal editors to attract papers that will boost their journal's profile.

The most popular index of a journal's status is the ISI Impact Factor (IF), produced by Thomson Scientific. It counts the total number of citations a journal's papers receive, and divides it by the number of papers the journal publishes. But the rise of online journals, coupled with sophisticated search engines that permit rankings of web resources, is triggering a wave of other measures. Last year, for example, physicist Jorge Hirsch of the University of California, San Diego, proposed a metric called the h-index for assessing the quality of researchers' publications (see Nature 436, 900; 2005).

Now Johan Bollen and his colleagues at the Research Library of Los Alamos National Laboratory in New Mexico are focusing on Google's PageRank (PR) algorithm. The algorithm provides

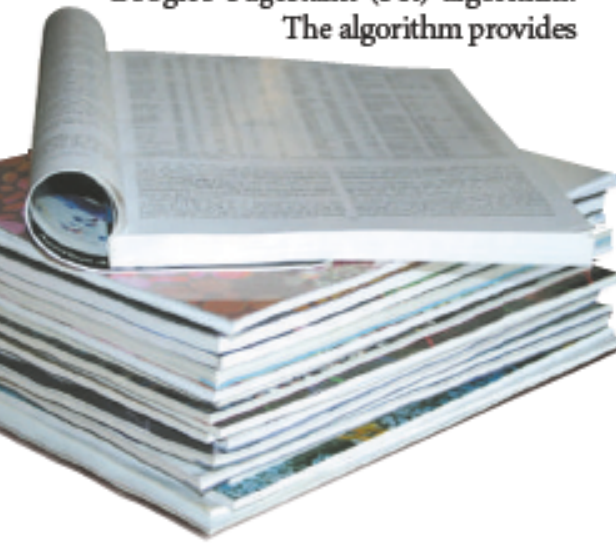

All for impact a single metric called the ISI Impact Factor is the most popular tool for ranking journals.

a kind of peer assessment of the value of a web page, by counting not just the number of pages linking to it, but also the number of pages pointing to those links, and so on. So a link from a popular page is given a higher weighting than one from an unpopular page.
The algorithm can be applied to research publications by analysing how many times those who cite a paper are themselves cited. Whereas the IF measures crude 'popularity', PR is a measure of prestige, says Bollen. He predicts that metrics such as the PR ranking may come to be more influential in the perception of a journal's status than the traditional IF. ${ }^{\alpha}$ Web searchers have collectively decided that PageRank helps them separate the wheat from the chaff," he says.

Bollen, however, proposes combining the two metrics. "One can more completely evaluate the status of a journal by comparing and aggregating the different ways it has acquired that status," he says. Some journals, he points out, can have high IFs but low PRs (perhaps indicating a popular but less prestigious journal), and vice versa (for a high-quality but niche publication). Using information from different metrics would also make the rankings harder to manipulate, he adds. So Bollen and his colleagues propose ranking journals according to the product of the IF and PR, a measure they call the Y-factor.

Whereas the top ten list by IF includes many journals that publish only review articles, or that serve primarily as data resources, the Y-factor ranking pushes up journals widely regarded as publishing prestigious original

\section{Plans to pare down climate centre anger UK ecologists}

Britain's ability to respond to the threats of climate change and pollution will be damaged if plans to downsize a key research institute go ahead, ecologists have warned.

The Centre for Ecology and Hydrology (CEH) risks losing a third of its 600 staff and half of its research sites if its main funder, the Natural Environment Research Council (NERC), follows through with reform proposals.

The council says the move will leave the centre with a more focused agenda and with critical science projects intact. But many are unconvinced, pointing out that a holistic approach to stud ying the impacts of climate change is more important than ever.

"We rely on the CEH's papers when making decisions," says Richard Jefferson, an ecologistat government-funded conservation body English Nature. "It seems ridiculous to be pruning this work back." His organization is one of several to have submitted objections to the proposal under a NERC-run consultationexercise that ended on 15 February.

Shaky finances have left the CEH with an annual deficit of around $\mathbf{E} 1$ million (US\$1.7 million) over the past three years. And the government wants the NERC and other research councils to shift resourcesfrom dedicated research institutes to competitive grants programmes.

To address these issues, the council wants to reduce the centre's core budget, currently around

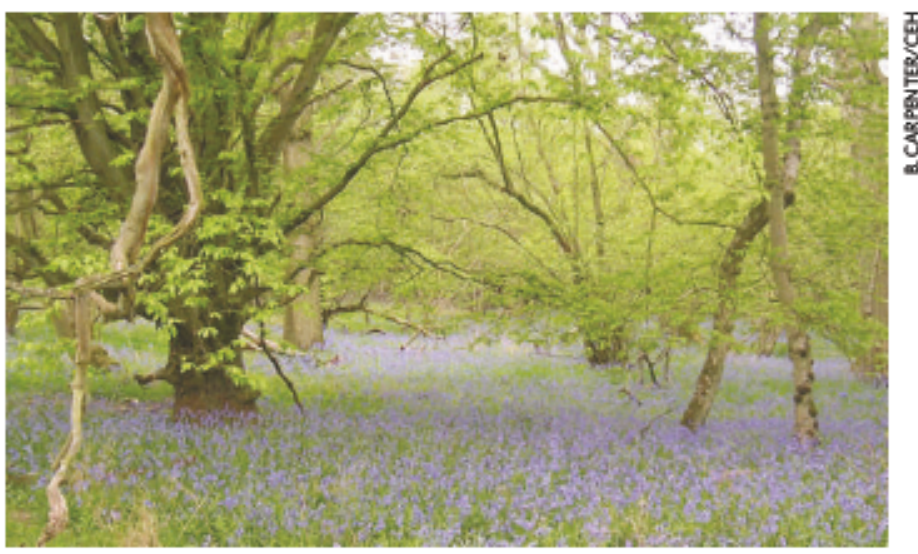

British countryside could suffer because of cut-backs to a key research centre.

$£ 20$ million, to $£ 15$ million. After consulting with the CEH, the NERC proposes to close its research sites at Banchory, Dorset, Monks Wood and Oxford, while retaining just four centres at Bangor, Edinburgh, Lancaster and Wallingford.

Once the 545 -million costs of the 


\begin{tabular}{|c|c|c|c|c|c|c|}
\hline \multicolumn{7}{|c|}{ TOP 10 JOURNALS AS RATED BY DIFFERENT METRICS } \\
\hline \multirow[b]{2}{*}{ Rank } & \multicolumn{2}{|r|}{ ISI Impact Factor } & \multicolumn{2}{|r|}{ PageRank $\left(\times 10^{3}\right)$} & \multicolumn{2}{|r|}{$Y$-factor $\left(\times 10^{2}\right)$} \\
\hline & Value & Journal & Value & Journal & Value & Journal \\
\hline 1 & 52.28 & Annu. Rev. Immunol. & 16.78 & Nature & 51.97 & Nature \\
\hline 2 & 37.65 & Annu. Rev. Biochem & 16.39 & LBial. Chem. & 48.78 & Science \\
\hline 3 & 36.83 & Physiol. Rev. & 16.38 & Science & 19.84 & N.Engl. J.Med \\
\hline 4 & 35.04 & Nature Rev. Mol. Cell Biol. & 14.49 & Proc. NatI Acad. Sci. USA & 1534 & Cell \\
\hline 5 & 34.83 & N.Engl. L.Med & 8.41 & Phys. Rev. Lett. & 14.88 & Proc. NatI Acad Sci. USA \\
\hline 6 & 3098 & Nature & 576 & Cell & 10.62 & L Biol. Chem \\
\hline 7 & 30.55 & Nature Med & 5.70 & N. Eng. L. Med. & 8.49 & JAMA \\
\hline 8 & 29.78 & Science & 4.67 & L. Am Chem. Soc. & 7.78 & Lancet \\
\hline 9 & 2818 & Nature Immunal. & 446 & L Immunol. & 7.56 & Nature Genet. \\
\hline 10 & 2817 & Rev. Mod. Phys. & 4.28 & Appl. Phys. Lett. & 65 & Nature Med \\
\hline
\end{tabular}

research (see table). For example, among horror stories from colleagues who have been physics journals, the IF places Reviews of subjected to evaluation by their departments Modern Physics at the top of the list, but the or national funding agencies which they felt Y-factor shifts the emphasis to rapid-publica- were strongly influenced by their personal IF, tion journals. Physical Review Letters is the he says. "Many fear this may eventually reduce most influential, with a Y-factor of $5.91 \times 10^{-2}$. (Dedaration of interest: Nature receives a very high Y-factor.)

Reinhardt Schuhmann, an

"PageRank helps web searchers separate the wheat from the chaff." the healthy diversity of viewpoints and research subjects that we would normally hope to find in the scholarly community."

editor on Physical Review Letters, calls the proposal " an interesting idea , but thinks that such metrics aren't really needed to prove status. "We don't pay much attention to impact factors, he says. But for Bollen, ranking journals more effectively by combining different ranking systems could help protect the integrity of science. He warns that scientists and funding agencies have used the ranking system well beyond its intended purpose. "We've heard

Jim Pringle, vice-president of development at Thomson Scientific, is also keen on the idea. ${ }^{\alpha}$ We have always advocated that research evaluation should be derived not only from metrics such as the IF but also from a thorough knowl-

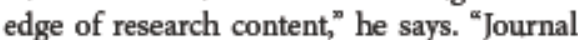
status metrics such as this, used in combination with our data, should be encouraged."

Philip Ball

www.arxiv.org/abs/cs.6L/0601030

closures have been met, the NERC will ploughthe savings into other programmes. But many researchers feel that the CEH's multidisciplinary work cannot be replicated elsewhere.

The centre brings together fields such as chemistry and wildlife management to answer broader environmental questions. Such an approach, many policy experts say, is the best way to generate predictions on issues such as climate-change impacts that can be used by politicians.

For example, at the CEHsite in Wallingford, west of London, researchers work with climate scientists and ecologists to model how global vegetation will respond to climate change. "The CEH provides the glue between the climate and vegetationmodels," says lan Woodward, an ecologist at the University of Sheffield who has worked with Wallingford researchers. "It's absolutely critical."

Although the site in Wallingford is not slated for closure, cuts will also be

made at the retained sites. So researchers there are nervous about their future.

PatNuttall, director of the CEH, sayss he is currently consulting with programme directors about possible cuts. She stresses that certain crucial projects, such as collecting long-term data sets on biodiversity and water quality, will be retained. Members of the NERC's 18-strong council, which will meet on 8 March to consider the consultation results, add that the reforms need not cause substantial damage. They argue that reducing duplication of research and high infrastructure costs will allow all

crucial CEH work to continue.

"This is not a carving back on science", says council member Sara Parkin, a programme director at Forum for the Future, a sustainabledevelopmentcharity in London, who backs the reform plan. "I've beenan environmental campaigner for 40 years. I know that we need quality evidence."

Jim Giles 